\title{
VOLUNTARY NURSING IN NATAL
}

\author{
E. V. Thompson B.Sc., R.G.N., R.M.
}

I believe we are the only Province where trained nurses run a purely voluntary district nursing service. Westville was first, we were followed by a branch starting in Hillcrest, then came Durban North, Amanzimtoti and the Bluff.

Each of these groups is organised and run by highly trained nurses; Durban North for example by Miss V. M. Borgen, who for many years was Chief Matron of King Edward VIII Hospital in Durban, at the helm. However, each group is run in a different way - to suit the local conditions and the nurses. But all are doing sterling work in the community; we are all on very friendly terms, and exchange ideas, etc., from time to time.

I can only speak with any authority about the Westville branch which 1 organise. Perhaps it would be easier if I started at the beginning.

We were actually conceived as a cross between Rugby and the Church! It happened thus: one Saturday morning a group of mothers, including some trained nurses, was standing watching school rugby when one of our number asked if the trained nurses knew of anyone or any organisation who could assist her to get a feeble father to a nursing home; he was to have an enema, and in those days the charge for the loan of a ward, and the nursing procedure, was $\mathrm{R} 8,00$. So, the problem of treating an infirm father and the cost involved sowed the first seed. Next, our local parson asked his congregation not only for money, but for talents, and some of us said we were trained nurses ... . and conception took place. However, many thought the idea was good enough to be extended to the whole community, so all denominations were approached and a notice was put in the local press calling a meeting for January, 1970. I was not present at that meeting, but was informed later that I was to be the organiser. A committee had also been elected. Apart from all being trained nurses, the only thing we had in common was that not one of us knew a thing about district nursing.

We called a second meeting and decided to find out as much as we could about district nursing - and to can- vas all the local doctors to get their reactions. These were varied, ranging from a doctor who expressed whole-hearted approval (and in the last 10 years we can count on one hand the number of patients he has sent us); to the doctor who said such a scheme would never work; he sent us our first patient, and I do not think there has been any time in the last 10 years when we have not had at least one of his patients.

The Methodist and Anglican churches each gave us $\mathrm{R} 50$, so we approached the hospital district nurses for guidance, and bought a bag similar to the one they used. It has never been used, in fact at present the bag is the container for an enema set! So that money was wasted and a lesson learnt.

We decided our services would be free, but if patients so wished they could give a donation as an expression of thanks.

By February 1970 we felt we were ready to go into business and published a notice in the local paper emphasising that our services could only be obtained through the patient's doctor, and we would attend all sick people of any race, providing they lived in the Municipality of Westville.

At first the doctors seemed to be reluctant to send us patients, but once we started, the Service grew steadily. In the early days we had many bright ideas - sending the nurse who lived nearest to the patient; or a nurse with a special training to a patient in need of that skill, only to find that the nurses were not available on the days they were needed. So we decided to ask every nurse to state the day, or days, in the week or month when she would be available: some work only one day a month, others once a week - or more. I then try to make up a roster to accommodate all our 40 nurses, teaming a girl without transport with one who has, a weak back with a strong one, matching skills and temperaments, etc. This roster is distributed to each member at the end of the month for the following month. In addition, each nurse has a full list of all the nurses and when they are available, so that if something unforeseen happens, she can change with a girl who nurses on the same day, and 
she then reports the changeover to me. All orders from doctors are supposed to come through me, although case cards are left with each patient, and the doctor is expected to write any change of treatment on the cards.

Having learnt the hard way - remember that wasted district bag! we limit our purchases of equipment to items that are dictated by patient need. Later, when we began to receive larger sums (donations in lieu of wreaths), we were able to buy more sophisticated equipment, trolleys, instruments, sterilisers, ripple beds, wheelchairs, etc. (A list of our equipment is given on a separate page.)

Now, with hospital expenses soaring and patients taking their discharge from hospital earlier, we find ourselves doing sterile dressings and keeping charts, i.e. for bloodpressure, urine testing, etc.

When the stock became too burdensome, we approached the Westville Town Board who gave us an equipment room on municipal premises and provided keys for the committee members. We also appointed an equipment officer.

In 1974 the Westville Municipality paid us a grant-inaid to help with equipment and general expenses.

We also approached a lawyer to draw up a simple constitution, and we appointed an auditor, who does our books free of charge.

About this time physiotherapists joined the staff, which made for a more thorough and comprehensive treatment.

The Service is a happy one, run with the minimum of rules and regulations. There are no forms to fill in, in triplicate, and no red tape. As there are no other social services in Westville, except for pre- and postnatal clinics for all races, our nurses are called upon to offer advice and help on all domestic matters, from marriage guidance to child care and diets.

This has meant the welding together of a group of women with diverse backgrounds into a wonderful community. I have never asked a nurse to help out and been refused, if it has been remotely possible for her to work. The service is offered for 5 days a week, with a skeleton staff to do dressings and attend very sick patients over the weekends, and there have always been volunteers for Christmas Day and Easter. The raw statistics of what we have done you will find on this page, and with more than 4000 nursings in the past year we are proud of the steady growth of the Service.

Whichever homes these girls visit, they are usually the most popular visitors of the day. Not only do they help the patient physically, but they give moral support to both patient and family and spiritual comfort to all.

Of course, in return we receive far more than we give - our rewards are above rubies and beyond price. In these so-called selfish and permissive days we have witnessed the courage of the 'ordinary man and woman in the street' as they strive to adapt their lives to chronic disease and to overcome crippling disabilities following accidents, etc. We have seen teenagers help to nurse parents, and watched the love and devotion which is the hallmark of a true marriage, as one partner has nursed the other through terminal disease.

All this has been an unforgettable experience, and has made us humble, sad, and glad, and has restored our faith in the future of mankind.

\section{Westville Voluntary Nursing Service}

$\begin{array}{lccr}\text { Year } & \begin{array}{l}\text { No. of } \\ \text { Patients }\end{array} & \begin{array}{l}\text { No. of } \\ \text { Nursings }\end{array} & \begin{array}{l}\text { No. o } \\ \text { Phone }\end{array} \\ 1970 / 71 & 29 & 699 & 944 \\ 1971 / 72 & 57 & 1235 & 1718 \\ 1972 / 73 & 81 & 1946 & 2055 \\ 1973 / 74 & 84 & 2276 & 2617 \\ 1974 / 75 & 89 & 2651 & 2673 \\ 1975 / 76 & 116 & 3291 & 3253 \\ 1976 / 77 & 81 & 3269 & 3662 \\ 1977 / 78 & 97 & 3680 & 3563 \\ 1978 / 79 & 90 & 4072 & 3796\end{array}$

Approximate yearly income R3 000

Approximate yearly expenditure R2 500

\section{Westville Voluntary Nursing Service}

\section{List of Equipment as at March, 1979.}

\begin{tabular}{lr} 
Sphygmomanometers & 5 \\
Stethoscopes & 5 \\
Surgical Beds & 6 (+ cot-sides, monkey \\
& \multicolumn{1}{c}{ chains) } \\
Wheelchairs & 15 \\
Sterilizers & 4 \\
Dressing trolleys & 2 \\
Surgical units & 3 \\
Dressing drums & 6 \\
Cardiac tables & 3 \\
Oxygen stand and gauges & 3 \\
Aspirator & 1 \\
Mist spray & 1 \\
Ripple Beds & 4 \\
Commodes & 17 \\
Bedpans & 21 \\
Urinals & 18 \\
Cradles, back-rests & 20 \\
Bean bag & 1 \\
Walking aids & 4 \\
Tripod walking sticks & 5 \\
Crutches & 13 \\
Infra-red lamps & 5
\end{tabular}

Sheepskins, mackintoshes, linen-savers (bought in bulk), disposable syringes, lotions, ointments, catheters, enemata apparatus, feeding mugs, etc. 